\title{
PERFORMANCES OF FREE AND IMMOBILIZED FRANGIPANI (PLUMERIA RUBRA) LATEX LIPASE IN PALM OIL LIPOLYSIS
}

\author{
Astri N. Istyami ${ }^{*}$, Ronny Purwadi ${ }^{2}$, Made T.A.P. Kresnowati ${ }^{2}$, Tirto Prakoso ${ }^{1}$, Tatang H. \\ Soerawidjaja ${ }^{1}$ \\ ${ }^{1}$ Department of Bioenergy Engineering and Chemurgy, Institut Teknologi Bandung, Jl. Raya Jatinangor \\ KM 20.75, Kabupaten Sumedang 45363, Indonesia \\ ${ }^{2}$ Department of Food Engineering, Institut Teknologi Bandung, Jl. Raya Jatinangor KM 20.75, \\ Kabupaten Sumedang 45363, Indonesia
}

(Received: July 2018 / Revised: October 2018 / Accepted: April 2019)

\begin{abstract}
Free fatty acid, which is an important intermediate product in the oleochemical industry, can be produced by hydrolysis of oil using lipase enzymes. This process is more economical and less energy consuming than the conventional process, i.e. noncatalytic thermal hydrolysis. While lipase from microorganisms requires a complex separation step, that from plants involves lower cost and easier handling. Nevertheless, no report has been published on the immobilization of plant latex-based lipase, while immobilization to increase the economic feasibility of microbial lipases has been widely reported. The aim of this study is to compare the performance of free and immobilized frangipani latex lipase in palm oil lipolysis. Immobilization was conducted by physical adsorption using hydrophobic supports and matrix encapsulation. The adsorption of frangipani latex lipase onto polypropylene and polyethylene beads was found to be ineffective, although the presence of the beads did slightly increase the degree of lipolysis. On the other hand, encapsulation with a calcium alginate matrix was effective in immobilizing particulate latex, although the calcium alginate beads were susceptible to breaking, causing contamination of the lipolysis product. To develop lipolysis technology utilizing frangipani latex lipase, free form lipase is more suitable in small-scale, stirred-tank lipolysis, while lipolysis with immobilized lipase from frangipani latex requires further modification, such as use of a packed bed reactor, circulated flow, or matrix modification.
\end{abstract}

Keywords: Fatty acids; Frangipani; Immobilized lipase; Latex lipase; Lipolysis

\section{INTRODUCTION}

As the world is showing great interest in sustainable industry, demand for oleochemical products has increased in the last decades. These products are slowly replacing petrochemical ones, including surfactants, plastics, lubricants, and even fuels. One of the most important reactions involved in the oleochemical industry is the conversion of triglyceride into fatty acids, which is encountered in most plant oil processing into derivative products. With the potential for increasing demand in the future, it is necessary to ensure that fatty acid production technology is energy-efficient, cost-efficient, and effective.

Noncatalytic thermal hydrolysis of triglyceride is the current technology employed for fatty acid production. It is a robust $\left(260^{\circ} \mathrm{C}, 50 \mathrm{bar}\right)$ and high-energy-consuming process

*Corresponding author's email: anistyami@che.itb.ac.id, Tel. +62-22-2500989, Fax. +62-22-2501438

Permalink/DOI: https://dx.doi.org/10.14716/ijtech.v10i3.2904 
(Barnebey \& Brown, 1948). The high temperature of the hydrolysis triggers unwanted reactions (Mounguengui et al., 2013), so a process involving milder conditions is preferable to avoid these drawbacks.

Lipase (EC 3.1.1.3) is an enzyme which catalyzes triglyceride hydrolysis (or lipolysis, when lipase is used). Lipases from bacteria and fungi have been studied for a long time, and some have been commercially produced. Although they are readily available in large quantities, their application in industrial lipolysis is limited by their high production cost (Seth et al., 2014). Other natural sources of lipase have emerged as alternatives; for example, plant seeds (Barros et al., 2010) and plant latex (Mazou et al., 2016). One remarkably active lipase source is frangipani (Plumeria rubra) latex particulate (Cambon et al., 2006). With the abundance of frangipani trees in warm regions, it is potentially feasible to develop small-scale production plants of fatty acids in rural areas.

Immobilization techniques has been utilized to improve the economic feasibility of enzyme utilization. They enable enzymes to be reused after reactions, and in some rare cases increase enzymes activity (Bastida et al., 1998). Among the immobilization methods, for instance adsorption, entrapment (encapsulation), cross-linking and covalent bonds, adsorption has been the most widely used technique. Besides being practical, it causes less deterioration to enzyme activity. In some cases, adsorption can also combined with other methods (Aliyah et al., 2016). Similar to adsorption, entrapment in a resin matrix is a technique with a minimum deterioration effect. Although immobilization increases the reusability of enzymes, it frequently decreases their activity. Considering these possibilities, it is important to evaluate the application of both immobilized and free enzymes.

Frangipani (Plumeria rubra) latex is a source of lipase which displays remarkable activity (Cambon et al., 2006). Our previous work shows that the lipolytic activity of frangipani latex is found in the particulate fraction. However, its solid particulates are easily dissolved in an oilwater mixture and cannot be retained after a lipolysis reaction. Immobilization, despite involving more process steps, might reduce operational costs by the recycling of frangipani latex lipase. On the other hand, non-immobilized lipase is easier to prepare, although it is only available for single use. To develop a lipolysis technology utilizing frangipani latex lipase, it is important to evaluate its performance, both in immobilized and free (non-immobilized) form.

The aim of this study is to compare the performance of immobilized lipase and free lipase from frangipani (Plumeria rubra) latex particulates. The feasibility of such immobilization is evaluated in the study, and the effect of denaturation is expected to be minimal. Immobilization was conducted with methods that are less susceptible to enzyme denaturation, namely adsorption and encapsulation (or entrapment). Frangipani latex lipase, in free or immobilized form, could be a potential biocatalyst for fatty acid production with low capital and operational costs, easy handling, and applicability in rural areas. An effective method for immobilizing latex lipase will also be applicable for lipase in solid form, such as dry extract lipase from microorganisms (Hermansyah et al., 2018).

\section{METHODS}

The study was conducted in four steps: preparation of crude lipase; immobilization of lipase; palm oil hydrolysis; and operational stability test.

\subsection{Preparation of Crude Lipase}

Lipase latex was collected from local trees in Bandung, Indonesia. Suspension of the latex was stored at $10^{\circ} \mathrm{C}$ for 5 days or until the particulates have been settled, then decantated to remove the liquid phase. The wet solid phase was dried with silica gel in a container at $4^{\circ} \mathrm{C}$, resulting in dry particulate. This form of latex is called 'crude lipase' or 'free lipase'. 


\subsection{Immobilization of Lipase}

The adsorption method was conducted with polypropylene and polyethylene beads, which had been been soaked in ethanol. Free lipase was mixed with the beads and phosphate buffer ( $\mathrm{pH}$ 7.00) for one minute. The mixtures were then incubated for 48 hours and filtered, producing immobilized beads.

For the encapsulation method, a sodium alginate aqueous solution $(0.02 \mathrm{~g} / \mathrm{mL})$ was prepared by mixing sodium alginate powder with the phosphate buffer $(\mathrm{pH} 7.00)$ until it was completely dissolved. Free lipase was added to $25.6 \mathrm{~mL}$ solution, stirred for 8 hours, pipetted dropwise to the $\mathrm{CaCl}_{2} 10 \%$ aqueous solution, and settled for 1 hour. The solids were filtered, washed and lyophilized for 8 hours in $0^{\circ} \mathrm{C}$, and were then ready for hydrolysis.

\subsection{Palm Oil Hydrolysis}

Lipase (free or immobilized) was added to 25.0 palm oil in a specific amount so that the concentration of crude lipase involved in the reactions was varied $(0 \mathrm{mg}, 22.5 \mathrm{mg}, 45.0 \mathrm{mg}, 67.5$ $\mathrm{mg}, 90.0 \mathrm{mg}$ and $112.5 \mathrm{mg} / 25 \mathrm{~g}$ palm oil). A buffer $\left(\mathrm{NH}_{3}-\mathrm{NH}_{4} \mathrm{Cl}\right)$ was added at a $1: 1(\mathrm{~mL} / \mathrm{g})$ ratio to oil and the mixture was stirred (at $950 \mathrm{rpm}$ ) at room temperature for 6 hours. A schematic illustration of the hydrolysis set up is shown in Figure 1. Each run was replicated three times and the lipase performance was evaluated by the degree of hydrolysis determination.

The hydrolysis product was settled for 15 minutes until two layers were formed. The upper layer was pipetted to a neutralized mixture of ethanol-chloroform and titrated with alcoholic $\mathrm{KOH}(0.1$ $\mathrm{N}$ ). The degree of hydrolysis was determined by Equation 1 (Rooney \& Weatherley, 2001). $V_{\text {КОH }}$ is the volume of alcoholic $\mathrm{KOH}$ in the sample titration $(\mathrm{mL}) ; M_{K O H}$ is the alcoholic $\mathrm{KOH}$ concentration $(\mathrm{N}) ; M M$ is the molecular mass of the palm oil fatty acids; $W_{t}$ is the sample weight $(\mathrm{g})$; and $f$ is the palm oil mass fraction in the reaction mixture. To evaluate the degree of hydrolysis in the non-enzymatic process, this analysis was also made for the reaction mixture of oil, buffer and immobilization supports.

$$
\text { Degree of hydrolysis }(\%)=\frac{V_{K O H} \times 10^{-3} \times M_{K O H} \times M M}{W_{t} \times f}
$$

\subsection{Operational Stability Test}

Lipolysis was conducted with the addition of $\mathrm{CaCl}_{2} 20 \%$ aqueous solution ( $1 \mathrm{~mL} / 2 \mathrm{gr}$ lipase) for 6 hours and the product was filtered with a Buchner funnel. The solid phase was weighed, washed with n-hexane and aqua dm, and reused in identical oil hydrolysis. The degree of hydrolysis was determined at the end of each reaction. The experiment was conducted with two replications and separate results were presented. At the end of the lipolysis reaction with the free lipase, the protein contents in the oil and aqueous phase were analysed by the Total Kjeldahl Nitrogen method.

\section{RESULTS AND DISCUSSION}

\subsection{Performances of Free and Immobilized Lipase}

The performances of free lipase (FL), immobilized lipase on polypropylene beads (PPL), immobilized lipase on polyethylene beads (PEL), and immobilized lipase in calcium alginate (CAL) are shown in Figure 1. All the frangipani latex lipase performances were evaluated at $\mathrm{pH}$ 8.25 . 


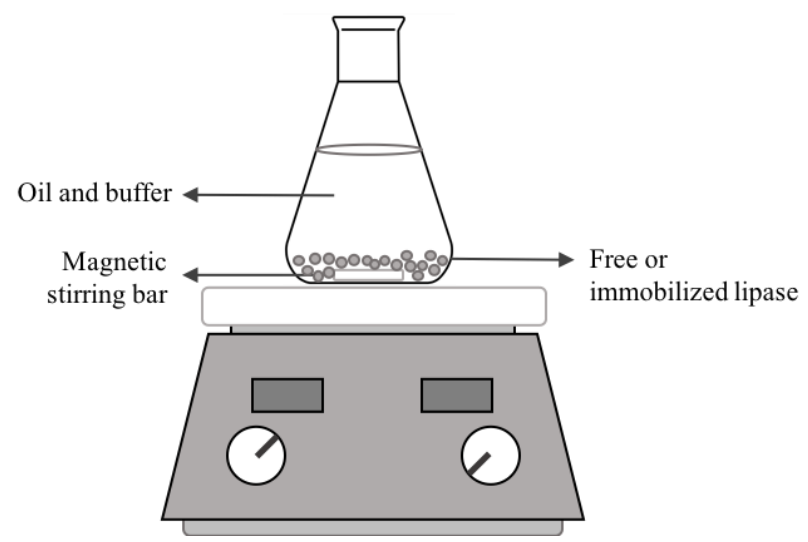

Figure 1 Schematic illustration of experimental set up

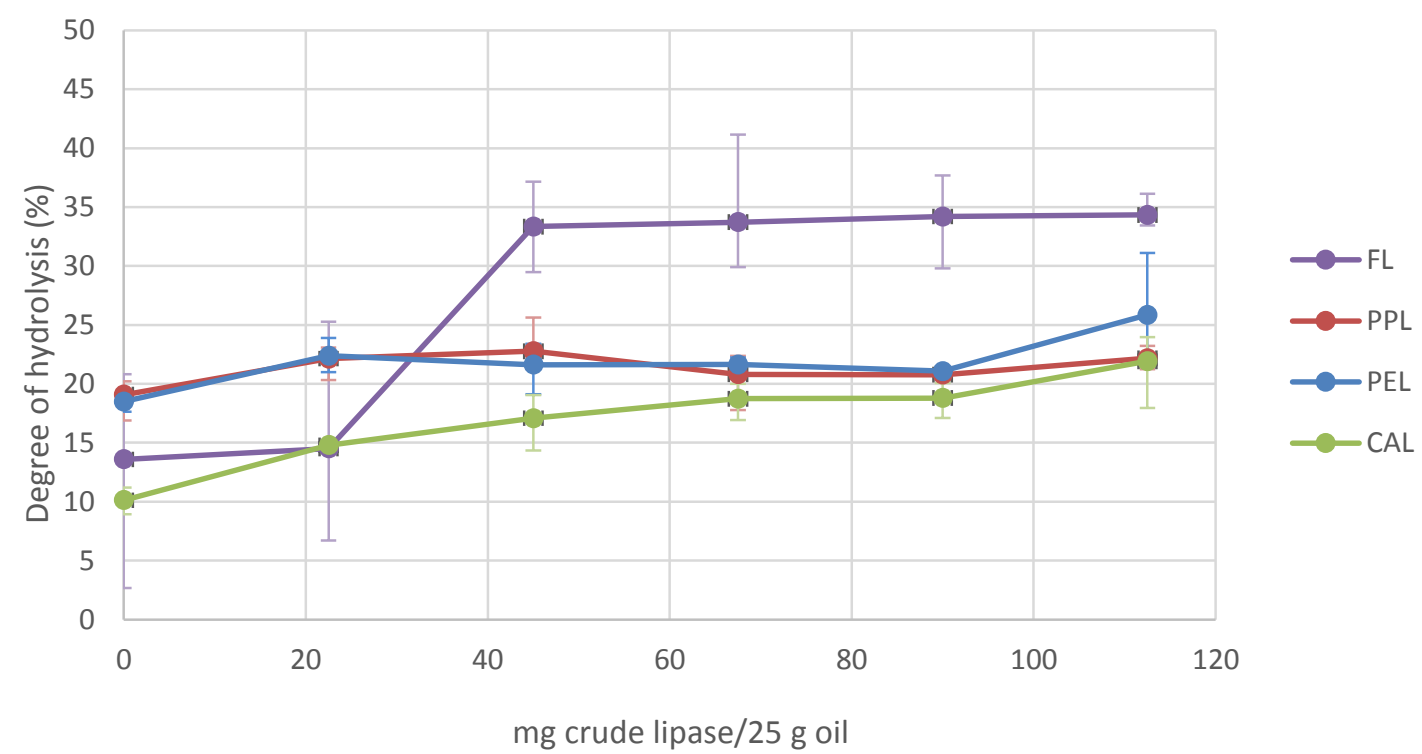

Figure 2 Degree of hydrolysis in over 6 hours reaction time with free and immobilized lipase

In the free lipase utilization, the degree of lipolysis was increased with the addition of crude lipase (Figure 2), which increased conversion significantly by $22.5-40.0 \mathrm{mg}$ crude lipase/25 gr oil, but had less effect above $40 \mathrm{mg}$ crude lipase/ $25 \mathrm{gr}$ oil. This indicates that the hydrolysis of triglyceride is an equilibrium reaction, which tends to show a rapid increase at lower lipase concentration and is relatively constant at higher concentration. A large error bar was clearly shown, indicating heterogeneity of the crude lipase performance, although the crude lipase was collected from the same tree and treated identically. External factors such as weather and level of exhaustion of the tree are natural conditions that could affect the quality of the biocatalyst utilization. Although performance dispersity can be minimized by a long reaction period or circulated flow, homogenous lipase activity is preferred in product quality assurance.

The reaction with $0 \mathrm{mg}$ crude lipase shows a 15\% degree of hydrolysis, indicating that the oil and buffer mixture was able to initiate hydrolysis without the presence of crude lipase. A basic buffer provides hydroxyl groups to initiate hydrolysis reaction (Barros et al., 2010). To confirm that the initiated hydrolysis was caused by the basic buffer, not by the contamination of the enzyme contained in the buffer solution, an experiment was conducted with a buffer made from sterilized water. The degree of lipolysis of the different oil and buffer mixtures is shown in Figure 3. An experiment was also conducted with a pH 7.00 buffer, which showed almost no lipolytic activity. 
This confirms that the non-enzymatic hydrolysis was facilitated by the basic conditions provided by the buffer solution.

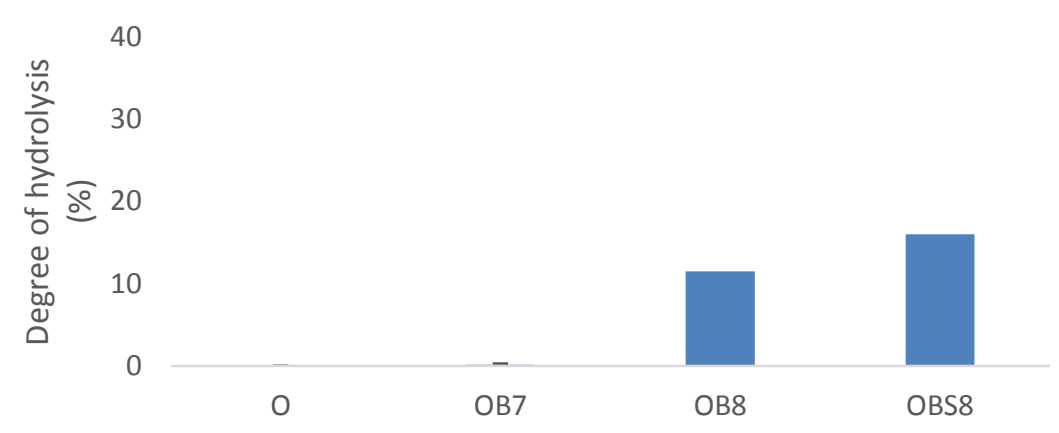

Figure 3 Degree of hydrolysis over 6 hours for different mixtures of oil and buffer $(\mathrm{O}=$ oil; OB7 $=$ oil and buffer with $\mathrm{pH} 7.00$; OB8 $=$ oil and buffer with $\mathrm{pH} 8.25$; OBS8 $=$ oil and sterilized buffer with $\mathrm{pH} 8.25$ )

Hydrophobic solids are reported to effectively adsorb microbial lipase (Manoel et al., 2015), being able to immobilize and purify lipase at the same time. This is advantageous in cases where the lipase is in crude form and contaminant removal is desired. Nevertheless, Figure 2 shows that the addition of immobilized lipase onto the polypropylene support causes no significant effect on the degree of hydrolysis. This indicates that adsorption with polypropylene beads was ineffective for the frangipani latex lipase, although it works on microbial lipase. It appears that adsorption on lipase from particulates is more difficult than lipase from liquids, indicating strong inhibition of mass transfer. Lipolytic activity in plant latex has been associated with its particulates and attempts to solubilize the lipolytic activity have been mostly unsuccessful (Abdelkafi et al., 2011).

Experiments were conducted to analyse the fatty acid produced in hydrolysis with polypropylene beads without lipase impregnation. They show that the presence of polypropylene beads increases the degree of hydrolysis by around $8 \%$, while ethanol soaking, incubation, and enzyme immobilization has almost no effect on the degree of hydrolysis. At the $0^{\text {th }}$ hour, no hydrolysis occurred, indicating that the effect of polypropylene on the degree of hydrolysis was developed during the reaction, not at the beginning of it. The presence of polypropylene beads increases the interaction between the agitated oil and water, facilitating more collisions between the molecules (Istyami et al., 2018). The positive effect of polypropylene beads on the degree of hydrolysis also confirms frangipani latex lipase as an enzyme with interfacial activation characteristics. Nevertheless, it is also confirmed that immobilization on polypropylene beads is not effective for frangipani crude latex.

As a comparison with polypropylene, polyethylene as the lipase immobilization support was also evaluated, as shown in Figure 2. Similar to the use of polypropylene beads, the addition of crude lipase onto polyethylene beads had almost no effect on the degree of hydrolysis, indicating ineffective lipase adsorption. Hydrolysis occurring in a reaction mixture with $0 \mathrm{mg}$ crude lipase was confirmed to have been caused by the presence of polyethylene beads, not the soaking in ethanol, incubation, or enzyme immobilization (Figure 4). It is concluded that hydrophobic supports are ineffective for the immobilization of particulate lipase. 


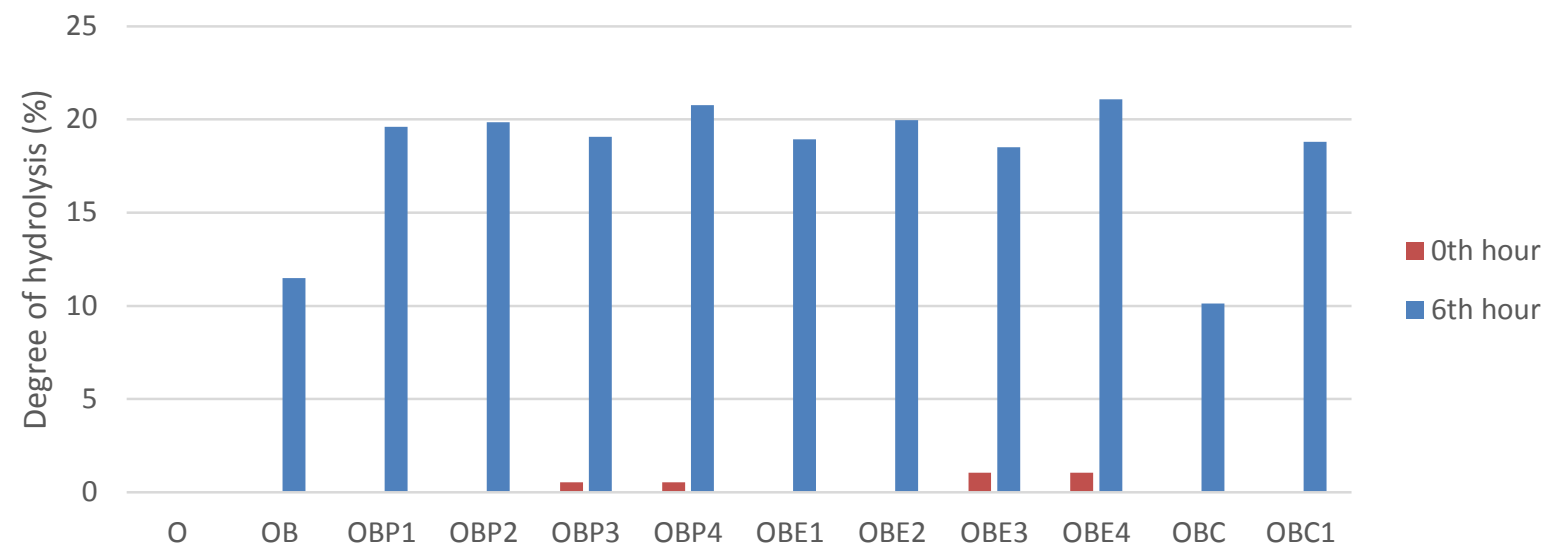

Figure 4 Degree of hydrolysis with immobilization supports and matrix (enzyme in calcium alginate)

O : oil

OB : oil and buffer

OBP1 : oil, buffer, and polypropylene beads

OBP2 : oil, buffer, and ethanol-soaked polypropylene beads

OBP3 : oil, buffer, and incubated polypropylene beads

OBP4 : oil, buffer, and lipase immobilized onto polypropylene beads

OBE1 : oil, buffer, and polyethylene beads

OBE2 : oil, buffer, and ethanol-soaked polyethylene beads

OBE3 : oil, buffer, and incubated polyethylene beads

OBE4 : oil, buffer, and lipase immobilized onto polyethylene beads

OBC1 : oil, buffer, and calcium alginate matrix

OBC2 : oil, buffer, and lipase immobilized into calcium alginate matrix

Figure 3 also shows the performance of immobilized lipase in the calcium alginate matrix in the palm oil lipolysis. Contrary to hydrophobic support, the addition of crude lipase to the matrix increases the degree of hydrolysis, indicating the effectiveness of lipase encapsulation. The error bars in this reaction are smaller than those of hydrolysis with free lipase, which suggests that encapsulation increases homogeneity in crude lipase lipolytic performance. Figure 4 confirms that the increasing degree of hydrolysis in the reaction with entrapped lipase was caused by immobilized enzymes, not the calcium alginate matrix. Immobilization in the matrix proved to be effective in entrapping frangipani crude latex lipase particulates.

Immobilization, despite increasing reusability, limits the contact between enzyme and substrate due to ineffective adsorption to the support (in adsorption) or mass transfer inhibition (in entrapment). In some cases, especially when cross-linking or in the covalent bond method, reduction of activity in immobilized enzymes might be caused by enzyme denaturation. On the contrary, several studies report that adsorption of microbial lipase on hydrophobic supports was able to increase enzyme activity through the selective-adsorption phenomenon (Jin et al., 2011). Nevertheless, based on the results in Figure 1, this phenomenon did not occurred with frangipani latex lipase, so free lipase was proven to be the most active form of frangipani latex lipase. However, immobilization in the calcium alginate matrix shows effectiveness, raising the possibility of enzyme reuse. In the following section, the activity and operational stability of free lipase and immobilized lipase will be compared. Considering that crude latex lipase immobilization was only effective with the calcium alginate matrix, operational stability was only evaluated for the encapsulated crude lipase. 


\subsection{Operational Stability of Free and Immobilized Lipase}

Enzyme recycling is an option to reduce operational process costs, especially when the enzyme cost is high. In this study, the performance of recycled enzymes (second cycle) was evaluated and compared with their initial performance (first cycle), as shown in Figure 5. The mass of recycled lipases is shown in Table 1. The lipases evaluated were free lipase (FL) and entrapped lipase with different concentrations, i.e. $45 \mathrm{mg} / 25 \mathrm{~g}$ oil (CAL45) and $90 \mathrm{mg} / 25 \mathrm{~g}$ oil. Each sample was evaluated with one replication.

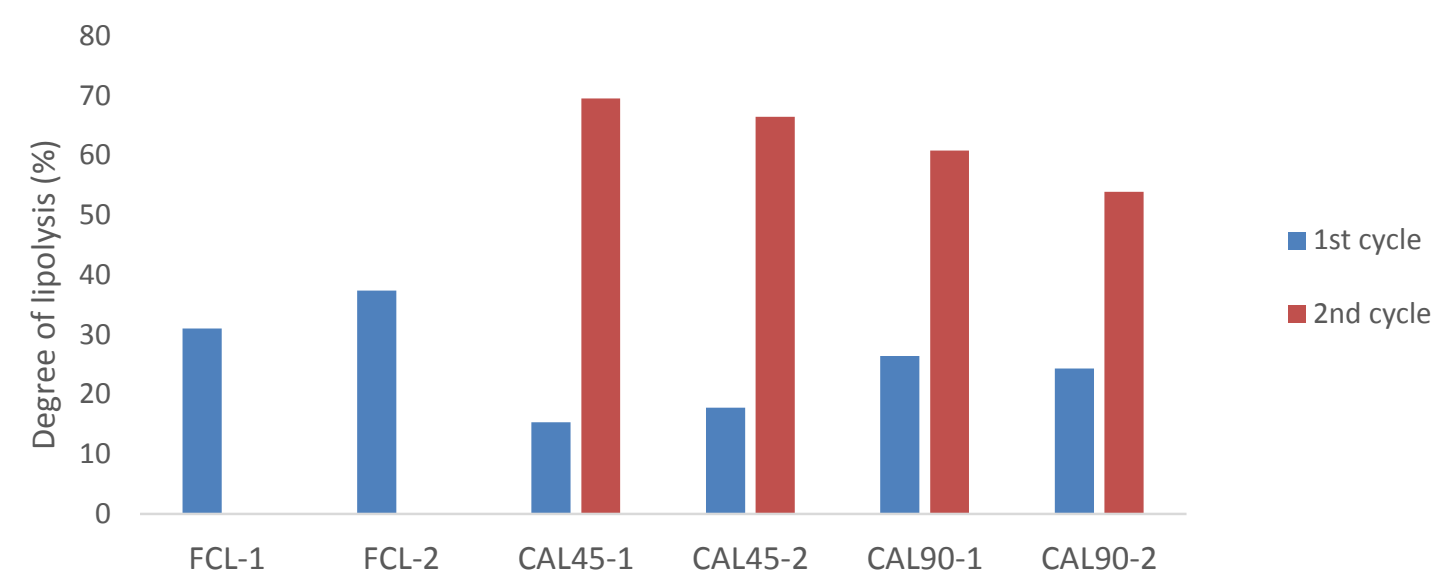

Figure 5 Operational stability of reused free lipase and reused crude lipase immobilized in the calcium alginate matrix

The slight difference between the first and second cycles indicates the heterogeneity of the crude latex lipase performance, caused by the divergent content of protein in each sample. Although particulate latex lipase has been reported to be naturally immobilized lipase (Abdelkafi et al., 2011), at the end of lipolysis reaction with free lipase, an attempt to recycle the crude lipase was unsuccessful. Lipase particulates was dissolved in the reaction mixture, both in the oil and aqueous phase. This was confirmed by analysis of the nitrogen content in the product of the lipolysis with free lipase, which showed that the oil phase contained $0.04 \%$ nitrogen, while the aqueous phase contained $0.94 \%$ nitrogen. Considering that lipase, like any other protein, contains nitrogen, it is concluded that most of the lipase was dissolved in the aqueous phase.

Table 1 Recycled enzyme mass after reaction

\begin{tabular}{lcc}
\hline & $\begin{array}{c}\text { Recycled enzymes } \\
(\mathrm{g}) \text { after first run }\end{array}$ & $\begin{array}{c}\text { Recycled enzymes } \\
(\mathrm{g}) \text { after second run }\end{array}$ \\
\hline FCL-1 & $0.00 \%$ & $0.00 \%$ \\
FCL-2 & $0.00 \%$ & $0.00 \%$ \\
CAL45-1 & $26.67 \%$ & $0.00 \%$ \\
CAL45-2 & $21.43 \%$ & $0.00 \%$ \\
CAL90-1 & $11.22 \%$ & $0.00 \%$ \\
CAL90-2 & $23.40 \%$ & $0.00 \%$ \\
\hline
\end{tabular}

The lipases encapsulated in calcium alginate were only successfully recycled after the first run, and completely dissolved in the second run. The matrix was broken due to 6 hours of agitation, which was confirmed by the thickening of the lipolysis product. Recycled lipase produces a higher degree of hydrolysis than fresh lipase, which suggests that the broken matrix exposed more lipase to the reaction mixture. A higher concentration of enzyme loading does not seem to affect the performance of entrapped lipase. Despite its effectiveness in immobilizing lipase, the calcium 
alginate matrix had the tendency to contaminate the products, which is contrary to the aim of immobilization. Breaking of the matrix can be avoided by increasing the density of the calcium alginate solution, producing a thicker matrix. Nevertheless, this will also increase mass transfer inhibition between the substrate and enzymes. Optimization of matrix strength and lipase activity is necessary when immobilized lipase is desired. To avoid agitation, oil flow can be circulated to provide enough contact with the enzymes. For small-scale lipolysis with a simple stirred tank, utilization of free lipase is more suitable. It has a low cost and shows good activity for the production of technical grade fatty acid.

\section{CONCLUSION}

Immobilization methods for frangipani crude latex have been compared. Adsorption of particulate latex lipase was ineffective, although it works on liquid microbial lipase. Immobilization was successfully achieved with encapsulation in a calcium alginate matrix, producing a lower, yet homogenous, degree of lipolysis. This enables recycling of lipase, although with limited frequency, and it is also susceptible to contamination from broken matrix. The performance of free and immobilized lipases has also been evaluated. Free lipases produce a higher, yet heterogenous, degree of lipolysis than immobilized lipases. They are more suitable for small-scale lipolysis with a stirred tank to produce technical grade fatty acid. Meanwhile, immobilization of latex lipase requires further modification, such as use of a packed bed reactor, circulated flow, or matrix modification.

\section{ACKNOWLEDGEMENT}

The authors are grateful to the Faculty of Industrial Technology, Institut Teknologi Bandung, for publication funding via a research grant awarded through the Research, Community Service and Innovation Program 2018 scheme, with Contract No. 0851b/I1.C06.2/PL/2018.

\section{REFERENCE}

Abdelkafi S., Barouh N., Fouquet B., Fendri I., Pina M., Scheirlinckx F., Villeneuve P., Carrière F., 2011. Carica Papaya Lipase: A Naturally Immobilized Enzyme with Interesting Biochemical Properties. Plant Foods for Human Nutrition, Volume 66(1), pp. 34-40

Aliyah, A.N., Edelweiss, E.D., Sahlan, M., Wijanarko, A., Hermansyah, H., 2016. Solid State Fermentation using Agroindustrial Wastes to Produce Aspergillus Niger Lipase as a Biocatalyst Immobilized by an Adsorption-crosslinking Method for Biodiesel Synthesis. International Journal of Technology, Volume 7(8), pp. 1393-1404

Barnebey, H.L., Brown, A.C., 1948. Continuous Fat Splitting Plants using the Colgate-Emery Process. Journal of the American Oil Chemists' Society, Volume 25(3), pp. 95-99

Barros, M., Fleuri, L.F., Macedo, G.A., 2010. Seed Lipases: Sources, Applications and Properties - A Review. Brazilian Journal of Chemical Engineering, Volume 27(1), pp. 15-29

Bastida, A., Sabuquillo, P., Armisen, P., Fernández-Lafuente, R., Huguet, J., Guisán, J.M., 1998. A Single Step Purification, Immobilization, and Hyperactivation of Lipases via Interfacial Adsorption on Strongly Hydrophobic Supports. Biotechnology and Bioengineering, Volume 58(5), pp. 486-493

Cambon, E., Gouzou, F., Pina, M., Barea, B., Barouh, N., Lago, R., Ruales, J., Tsai, S.W., Villeneuve, P., 2006. Comparison of the Lipase Activity in Hydrolysis and Acyl Transfer Reactions of Two Latex Plant Extracts from Babaco (Vasconcellea $\times$ Heilbornii Cv.) and Plumeria Rubra: Effect of the Aqueous Microenvironment. Journal of Agricultural and Food Chemistry, Volume 54(7), pp. 2726-2731 
Hermansyah, H., Maresya, A., Putri, D.N., Sahlan, M., Meyer, M., 2018. Production of Dry Extract Lipase from Pseudomonas Aeruginosa by the Submerged Fermentation Method in Palm Oil Mill Effluent. International Journal of Technology, Volume 9(2), pp. 325-334

Istyami, A.N., Kresnowati, M.T.A.P., Prakoso, T., Soerawidjaja, T.H., 2018. The Use of Hydrophobic Beads in Triglyceride Hydrolysis. Journal of Advances in Technology and Engineering Research, Volume 4(1), pp. 9-16

Jin, Q., Jia, G., Zhang, Y., Yang, Q., Li, C., 2011. Hydrophobic Surface Induced Activation of Pseudomonas cepacia Lipase Immobilized into Mesoporous Silica. Langmuir, Volume 27(19), pp. 12016-12024

Manoel, E.A., Dos Santos, J.C.S., Freire, D.M.G., Rueda, N., Fernandez-Lafuente, R., 2015. Immobilization of Lipases on Hydrophobic Supports Involves the Open Form of the Enzyme. Enzyme and Microbial Technology, Volume 71, pp. 53-57

Mazou, M., Djossou, A.J., Tchobo, F.P., Villeneuve, P., Soumanou, M.M., 2016. Plant Latex Lipase as Biocatalysts for Biodiesel Production, African. Journal of Biotechnology, Volume 15(28), pp. 1487-1502

Mounguengui, R.W.M., Brunschwig, C., Barea, B., Villeneuve, P., Blin, J., 2013. Are Plant Lipases a Promising Alternative to Catalyze Transesterification for Biodiesel Production? Progress in Energy and Combustion Science, Volume 39(5), pp. 441-456

Rooney, D., Weatherley, L.R., 2001. The Effect of Reaction Conditions upon Lipase Catalysed Hydrolysis of High Oleate Sunflower Oil in a Stirred Liquid-liquid Reactor. Process Biochemistry, Volume 36(10), pp. 947-953

Seth, S., Chakravorty, D., Patra, S., 2014. An Insight into Plant Lipase Research - Challenges Encountered. Protein Expression and Purification, Volume 95, pp. 13-21 